\title{
An intelligent algorithm for accurate forecasting of short term solid waste generation
}

\author{
Mohana Fathollahi*, Saeed Heidari Farsani and Ali Azadeh
}

School of Industrial Engineering, College of Engineering, University of Tehran, Tehran, Iran

\begin{tabular}{l}
\hline C H R O N I C L E \\
\hline Article history: \\
Received: October 1, 2017 \\
Received in revised format: No- \\
vember 16, 2017 \\
Accepted: May 21, 2018 \\
Available online: \\
May 21, 2018 \\
\hline Keywords: \\
Waste Prediction \\
Municipal Solid Waste (MSW) \\
Regression approach \\
Artificial Neural Network \\
Adaptive Neuro-Fuzzy Inference \\
System
\end{tabular}

\section{Introduction}

Municipal solid waste (MSW) generation and management is affecting all countries around the world. Big portion of MSW is the "consumption trash" in daily life that is produced by residents such as bottles, kitchen garbage, newspaper, school trash, old furniture, newspaper, product packaging and etc. Production and manufacturing of these products also generate a lot of solid waste. For the fact that consumption seems to be ever increasing, waste production has become an important issue and their disposal is a big concern, that may threaten the sustainable development of society (Takahashi et al., 2012). Factors like economic development, urbanization, living and education standards improvement and countries' infrastructures have caused an increase in amount of generated waste and complexity of municipal solid waste. Nowadays, governments, pollution agencies, and even residents are becoming more concerned on managing of MSW (Erdogan et al., 2008; Manaf et al., 2009). In general, to dispose

\footnotetext{
* Corresponding author.

E-mail address: mhn.fathollahi@alumni.ut.ac.ir (M. Fathollahi)

C 2017 by the authors; licensee Growing Science, Canada doi: $10.5267 /$ j.ijdns.2017.1.006
}

\begin{abstract}
Municipal solid waste management has become a global concern during the past decades in many countries such as Canada and waste management technological advancements and regulations have been increased. Solid wastes emit greenhouse gases which result in global climate
change, pollution of air and water which has tremendous negative impact on human health. Due to the excessive urbanization and fast economic development, municipal solid wastes have been increased in developing countries. In order to manage this emerging issue, polluted countries nicipal solid of legislations and policies toward solid wastes. Accurate prediction of future mumunicipal solid waste generation in city of Tehran, the most populated city in Middle East. Three methods are explored in this paper to analyze the past solid waste time-series analysis: regresThe first neural networks models. The second method utilizes the past data as training example of neural network to find autocorrelation among target; lastly, the neuro-fuzzy learns the relation of data using fuzzy-rule. Mean Absolute Percentage Error (MAPE) metric is used to evaluate the performance. Finally, analysis of variance (ANOVA) and Duncan experiment are performed to
\end{abstract}

(C) 2017 by the authors; licensee Growing Science, Canada. 
MSW four practices are followed: (1) reduction of solid waste, this can be for example done by educating people to use less plastic packaging, buy reusable water bottles, or donate their old clothes or old furniture to charities instead of throwing them in the trash. (2) Recycling items by carefully separating different materials. For example, different components of electronic appliances can be reused (Nasiri et al., 2017a). Or dense plastic materials can be converted to other materials that are used in outdoor furniture. (3) Combustion: in this process solid waste is burned to generate energy. (4) Reduction the number of landfills, and instead having larger landfills because the amount of solid waste would remain constant (Rabbani et al., 2017).

Analysis of waste is not only valuable for city management; it also often leads to interesting observations. For example, Rhyner (1992) has predicted the commercial, residential, industrial wastes in Brown County, Wisconsin, USA. The author has observed that monthly amount of residential and commercial waste in the summer was $23.8 \%$ more than average and $19.8 \%$ lower than average in winter months. Similarly, Gómez et al. (2009) has analyzed waste generation in different seasons in Chihuahua (a city in Mexico). The statistics showed that the quantities of waste generation in high temperature season (April) were 28\% higher than in low temperature season (January). Assessment of generation of solid waste are not limited to annual or monthly prediction, for example, Denafas et al. (2014) have studied the seasonal generation of different types waste such as organic, inorganic, wood, glass, and metal waste. The data was analyzed by time series models such as non-parametric seasonal exponential smoothing, winter's additive, and winters multiplicative methods. Climate conditions play a critical role in composition of municipal solid waste in every place. Visvanathan and Trankler (2003) have compared the solid waste generating and management in tropical countries in dry and rainy seasons.

Regression is one of the widely used approaches in modeling time series. In the waste prediction, 'time' is independent variable and waste in the past years is the only dependent variable. To estimate parameters of a regression model, the first step is to inspect the trend of the data that could be linear, polynomial, logistic, etc. These trends differ in terms of number of parameters and complexities in estimating these parameters. For example, a three-parametric time series model was applied by (Skovgaard et al., 2005). Rimaityte et al. (2012) have leveraged the combination of seasonal exponential smoothing and autoregressive integrated moving average approaches to forecast the waste generation in two quickly developing cities of Eastern European. They also observed that time series methods are accurate enough to predict the weekly variation of data, while more advanced approach such as regression is appropriate for yearly forecast. Mwenda et al. (2014) have applied ARMA/ARIMA and Exponential Smoothing approaches on waste data from July 2008 to June 2013 in Arusha, Tanzania. In addition, in the past few years researches are exploiting more advance technique such as Artificial Neural Network (ANN) to predict time series. ANN is a powerful technique in machine learning that has been used in many domains. The first introduction of ANNs dates back to 1940s (McCulloch and Pitts, 1943). The growing interest in this tool was stopped about 1960s when Minsky and Papert (1969) highlighted that it is not effective to train networks of practical size. While in mid-1980s, Rumelhart et al. (1986) again discovered a calibration algorithm that robustly train networks of practical sizes and complexities, once again ANNs became popular and even more research and models utilized this tool. Training algorithm in ANNs tries to model the complex relationship between independent variables (input to the network) and dependent variables (output of network) if there is sufficient data provided. Therefore, to model complex problems in economic, finance, medical diagnosis ANN models are widely used (Toth-Nagy et al., 2006). Application of ANNs in waste management has pervaded recently, prediction the rate of leachate flow in solid waste in Istanbul, Turkey (Karaca \& Özkaya, 2006); utilizing multilayer perceptron neural networks to estimate energy content of Taiwan MSW (Shu et al., 2006); examining the characteristics of Hydrogen chloride $(\mathrm{HCl})$ emitted from coal co-fired fluidized beds using back propagation neural networks (Chi and ZHANG, 2005); use of models based on ANN to assess recycling capacity and recycling strategy (Liu et al., 2002); and estimation of heat generation from urban solid waste using ANN and multi-variable linear regression in Nanjing, China. Dong et al. (2003) are all examples of application of ANN in waste management domain. Our work is similar to Noori et al. 
(2009a), where the authors have compared ANN with multivariate linear regression model in weekly prediction of waste in city of Tehran, Iran. Noori et al. (2009b) in another article extended their work to predict the waste generation in Tehran for longer time period, one or more months. They provide the experiments based on Wavelet Transform-ANN and WT-ANFIS approaches. Pamnani and Meka have presented that generating the solid waste depends on some variables for example: population, socio economic condition of the area and geographic location of it. These variables are assumed independent to each other. In this study, static and dynamic ANN models is presented to estimate MSW generation, in which Levenberg-Marquardt algorithm is used to train the neural network. Changes in population and income are important to predict the solid waste (Beede and Bloom, 1995). In this work, it has shown that $1 \%$ increase in population will increase the solid waste by $1.04 \%$; and $1 \%$ increase in per capita income causes solid waste generation to increase by $0.34 \%$. The author proposed static and dynamic model of ANN to forecast the MSW of a small city and closed by villages in India. Qdais et al. (2010) collected the historical data over 177 days of a plant in Jordan to feed in a two layers ANN to estimate gas production, genetic algorithm is also used as a tool to optimize the Methane size. There are several optimization approach in ANN, such as: resilient back-propagation (RP), scale conjugate gradient (SCG), one step secant (OSS), and Levenberg-Marquardt (LM), these approaches are compared by Noori et al. (2010) to forecast weekly solid waste generation in Mashhad Iran. The MSW historical data in developing countries are incomplete usually. Therefore, they need a prediction model to be robust against missing data. Antanasijević et al. (2013) trained an ANN model that is able to handle missing or incomplete data in countries such as Bulgaria and Serbia. In this model the correlation of other parameters such Gross domestic product, domestic material consumption, and productivity of resource are used to handle missing data in prediction of waste generation.

\section{Methodology}

There are 22 districts in Tehran metropolis with millions of people and increasing amount of solid waste volume. Our initial goal was to process the data of all districts, but since accessing to data was not possible in all districts, inputs were limited to data of the last six years of district 1.In this paper, three methods are utilized to analyze a solid waste time-series: regression, ANN, and ANFIS methods. In summery the following steps are done to predict waste generation:

- Step1: Collected data usually are quite noisy, so they should be first preprocessed and transformed to the same scale.

- Step2: Input and output variables are specified based on the collected data Daily solid wastes between 2006 to 2011 are considered as input and data of 2012 are the corresponding output.

- Step3: In the first experiment, we compare several methods of regression such as: linear, Logarithmic, Growth curve and etc. MAPE and R-squared metrics are then utilized to compare their performance. Similarly, the best structures of ANNs and ANFIS models are selected based on the minimum MAPE.

- Step 4: The models are compared by changing the percent of training and test data set.

- Step 5: Finally, ANOVA and Duncan test are used to verify and validate the results and select the appropriate model. Figure 1 shows the steps of the presented approach.

\subsection{Regression models}

One of the traditional approaches to develop a predictive model for time series is statistical regression model. The goal is to predict the future value, Y, based on the past observation of variables, X. In the regression function, f specifies the relation between Y and X (Kutner et al., 2004). For example, in linear regression, the output only depends on the weighted input variables. These parameters, $\beta_{\mathrm{i}}$, are estimated by least squared method:

$$
\mathrm{Y} \approx \mathrm{f}(\mathrm{X}, \beta)
$$


- Preprocessed and transform data to reach the appropriate data

- Specify the input and output variables

- Train three models consist of regression, ANN and ANFIS

- Models are compared based on MAPE metric

- ANOVA and Duncan test are used to verify and validate the results

Fig. 1. Flowchart of solid waste prediction

In Table 1, several regression methods are compared based on the MAPE and R-squared metric. Where MAPE is defined in the Eq. (2).

$$
\text { MAPE }=\frac{1}{\mathrm{~N}} \sum_{\mathrm{i}=1}^{\mathrm{N}}\left|\frac{\mathrm{Y}_{\mathrm{t}}-\widehat{Y}_{t}}{\mathrm{Y}_{\mathrm{t}}}\right|
$$

In this Equation $Y_{t}, \widehat{Y}_{t}$ and $\mathrm{N}$ are the accurate data, estimated value and number of training examples, respectively.

\section{Table 1}

Values of MAPE of trend line models

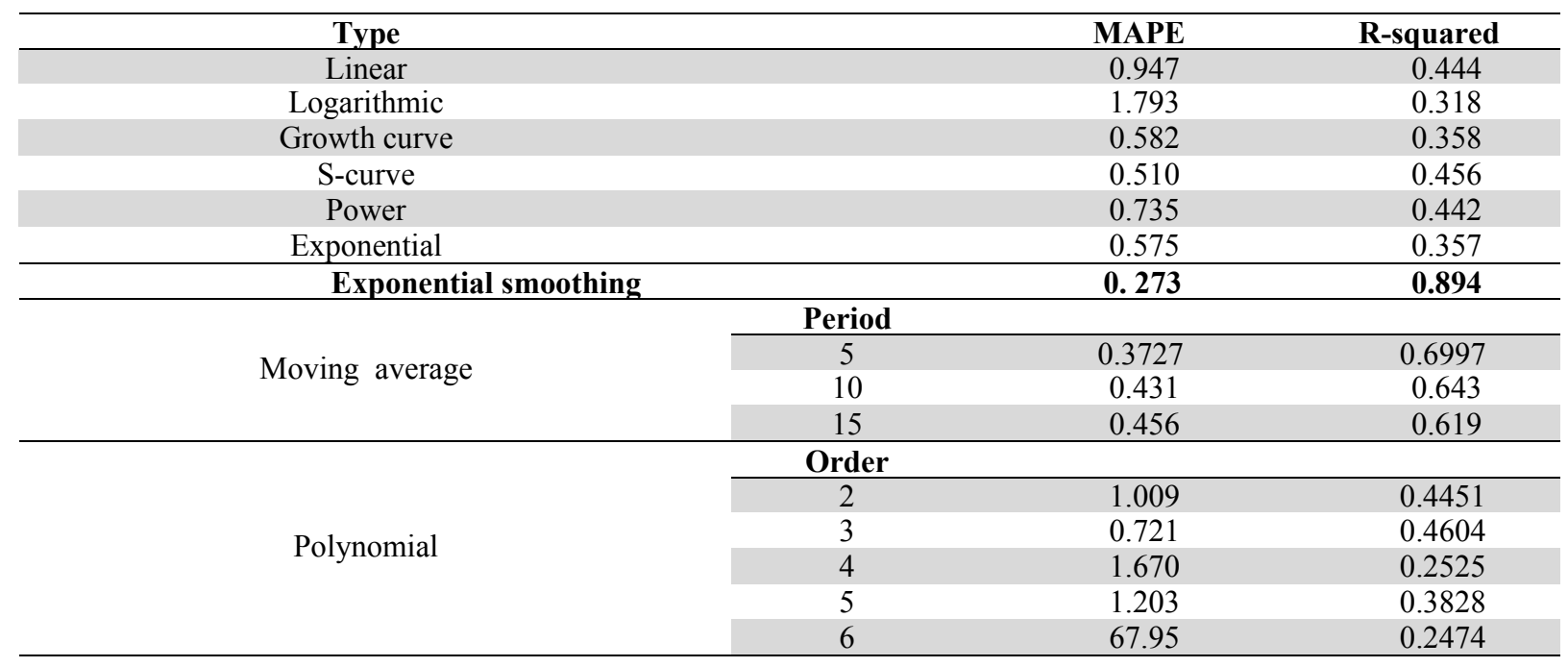

According to this table, Exponential Smoothing has the minimum MAPE and maximum R-squared value compared to other approaches.

\subsection{Artificial Neural Network}

Artificial neural network is a branch of machine learning that is able to recognize the complex pattern in data. Some of the attributes that make this method appropriate to solve complex problems are learning ability, generalization, parallel processing and error endurance (Strouboulis et al., 1992). Basically, the human brain is the source that ANN models try to imitate. Generally, there are two types of ANN: feed forward and recurrent. The first type is the simples and most widely used ANNs which is often called MLP-ANN (multi-layer perceptron-ANN). In this model the information only moves forward; 
i.e. from input to hidden and finally to output layer (Sy, 2006). While in recurrent ANN, there is a backward connection in the network which form a directed circle. In this work we only focus on feed forward ANN. Although a lot of examples with less noise are required to train ANN; usually this method creates better results in comparison with other approaches. The architecture of ANN is composed of three types of layers of neurons: Input, hidden and output layer. The 'input layers' are directly connected to the data. These layers are connected to the neurons in the 'hidden layers' using some weighted connections (Dreiseitl \& Ohno-Machado, 2002).

The main task of a hidden layer is to model the complex relation between input and output variables and recognize the existent pattern in the data (Bandyopadhyay \& Chattopadhyay, 2007). Output layer in this experiment is the predicted waste value. For example, suppose that you would like to use the amount of generated waste in the last three months and predict the amount of waste that will be generated in the next month. Therefore, you would need a neural network with input layer with three nodes and output layer with just one node. Unfortunately, there is no clear guideline of selecting the number of hidden layers and neurons in that layer. These parameters usually are selected by trial and error. In Eq. (3) represents relationship between the inputs and outputs (Azadeh et al., 2017).

$$
x_{t}=\beta_{0}+\sum_{j=1}^{m} \beta_{j} \cdot g\left(\beta_{0 j}+\sum_{i=1}^{n} \beta_{i j} \cdot x_{t-i}\right)+\epsilon_{t}
$$

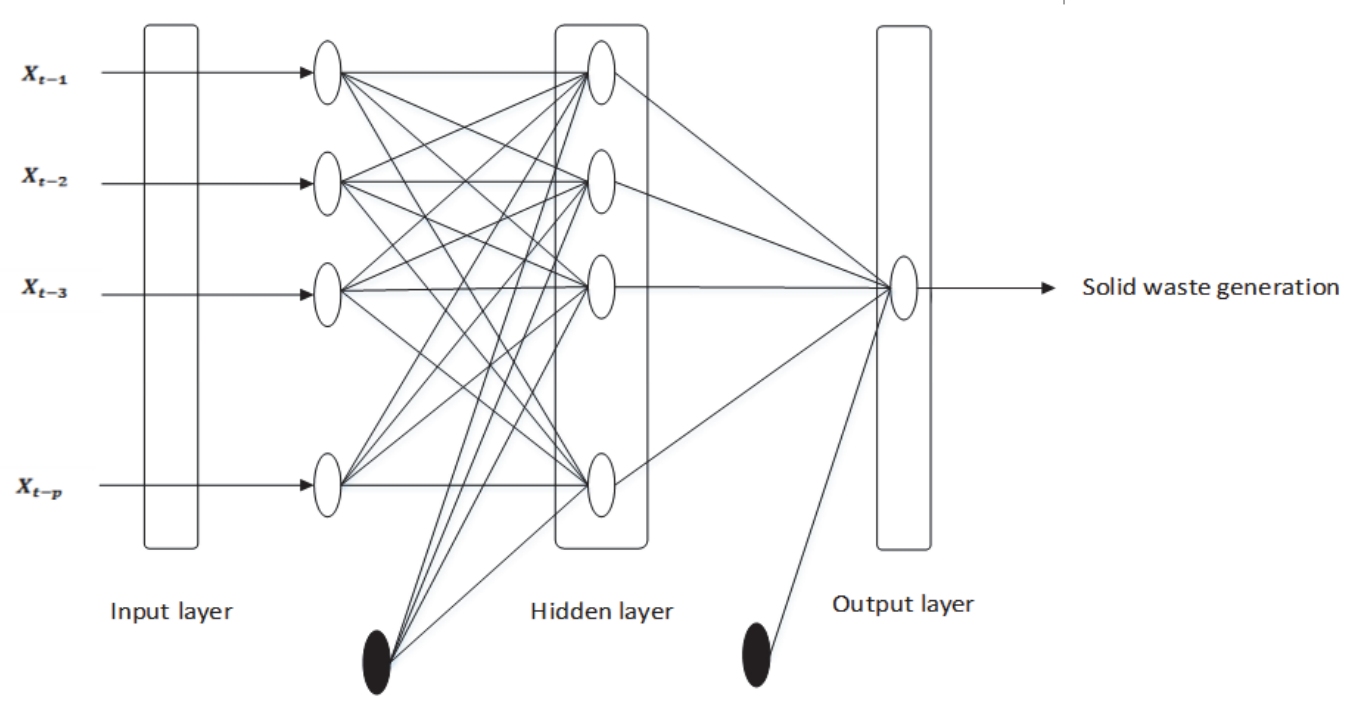

Fig. 2. Architecture of a feed-forward artificial neural network

The parameters of the hidden layers and output layer are represented by $\beta_{\mathrm{ij}}$ and $\beta_{\mathrm{j}}$ respectively. The number of input nodes and the number of output nodes are represented by $\mathrm{n}$ and $\mathrm{m}$ respectively. The transfer function of the neurons ' $\mathrm{g}$ ' can take various forms, the log-sigmoid and tangent-Sigmoid functions usually show better performance compared to other type of functions. To calculate the weights of the network in the Eq. (2), we partition the data into training and test sets. In this study, $80 \%$ of the data is used as the training set and the rest of it as test data set. We design 12 different experiments; in each one we change the number of neurons, number of hidden layers, and training algorithm. We used linear activation function in the output layer. Table 2 illustrates these models as well as their MAPE metric (Hornik et al., 1989). In this experiment, MATLAB® 2014 neural network toolbox is used for our implementation.

Based on Table 2, network architecture 1 has the least MAPE and is selected as representative of ANN category for our further experiments. This model has one hidden layer with 5 neurons, and LevenbergMarquardt is used as optimization function. 
Table 2

Effect of hyper-parameters of ANN

\begin{tabular}{cccccccc}
\hline $\begin{array}{c}\text { Model } \\
\text { No. }\end{array}$ & $\begin{array}{c}\text { Training } \\
\text { Function }\end{array}$ & $\begin{array}{c}\text { Number of } \\
\text { Hidden } \\
\text { layers }\end{array}$ & $\begin{array}{c}\text { Training } \\
\text { function of } \\
\text { first hidden } \\
\text { layer }\end{array}$ & $\begin{array}{c}\text { Neurons } \\
\text { in first } \\
\text { layer }\end{array}$ & $\begin{array}{c}\text { Training function } \\
\text { of second hidden } \\
\text { layer }\end{array}$ & $\begin{array}{c}\text { Neurons } \\
\text { in second } \\
\text { layer }\end{array}$ & Performance \\
\hline No. 1 & GD & $\mathbf{1}$ & Logsig & $\mathbf{5}$ & & $\mathbf{0 . 2 5 6}$ \\
\hline No. 2 & LM & 1 & Tansig & 4 & Logsig & 5 & 0.331 \\
No. 3 & LM & 2 & Tansig & 5 & tansig & 6 & 0.441 \\
\hline No. 4 & BFG & 2 & Logsig & 6 & tansig & 10 & 0.449 \\
No. 5 & GD & 2 & Tansig & 10 & & 0.501 \\
\hline No. 6 & LM & 1 & Logsig & 25 & tansig & 9 & 0.325 \\
No. 7 & GD & 1 & Tansig & 20 & & 0.310 \\
\hline No. 8 & GDA & 2 & Logsig & 9 & tansig & 14 & 0.496 \\
No. 9 & LM & 1 & Tansig & 3 & tansig & 12 & 0.326 \\
\hline No. 10 & BFG & 2 & Logsig & 14 & & 0.295 \\
\hline No. 11 & GD & 2 & Tansig & 12 & & 0.298 \\
\hline No. 12 & LM & 1 & Logsig & 37 & & 0.382 \\
\hline
\end{tabular}

LM: Levenberg-Marquardt back propagation; GDA: Gradient descent with adaptive learning rule back propagation; BFGS: quasi-Newton back propagation; GD: Gradient descent back propagation.

\subsection{Adaptive Neuro-Fuzzy Inference System}

One of the drawbacks of ANN approach is that it is hard to interpret what the network has learned. Adaptive Neuro-Fuzzy Inference System is a type of artificial neural network that applies fuzzy inference techniques to model the data. It is developed by Jang in 1993 and it has inherited the learning strength from ANN and ability to represent structured knowledge from fuzzy inference Tiwari et al. (2012). ANFIS maps the input to a middle space using input membership functions and this middle space is later maps to output through output membership functions. In contrary to the ANN, it contains five different layer types and uses a hybrid-learning mode (Gradient descent and least square) to learn the parameters of the network (Azadeh et al., 2010).

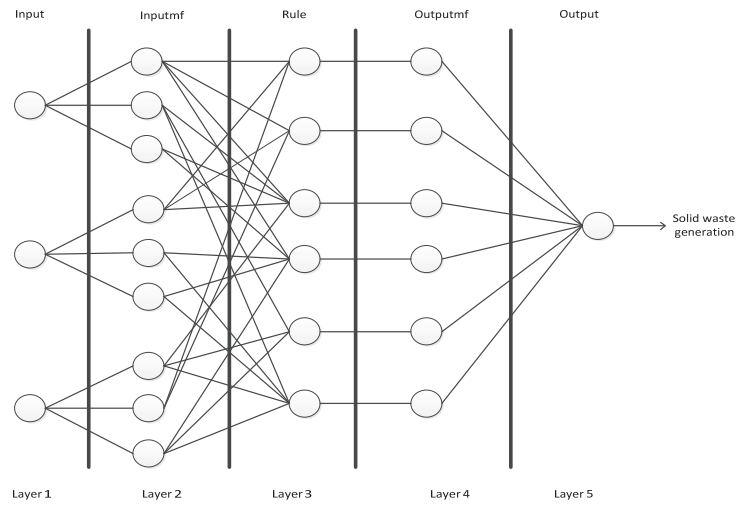

Fig. 3. Structure of ANFIS model

Structure of ANFIS is shown in Fig. 3. Similar to ANN model, in ANFIS model 12 different architectures have been designed and compared based on MAPE metric in Table 3. The data is partitioned to $80 \%$ and $20 \%$, representing training and test set respectively. According to Table 3 , structure 10 of ANFIS method has the minimum MAPE metric. The selected model uses Gaussian membership function for input layer, linear membership function for output layer, subtractive clustering in initial fuzzy inference system and back propagation in optimization method. 


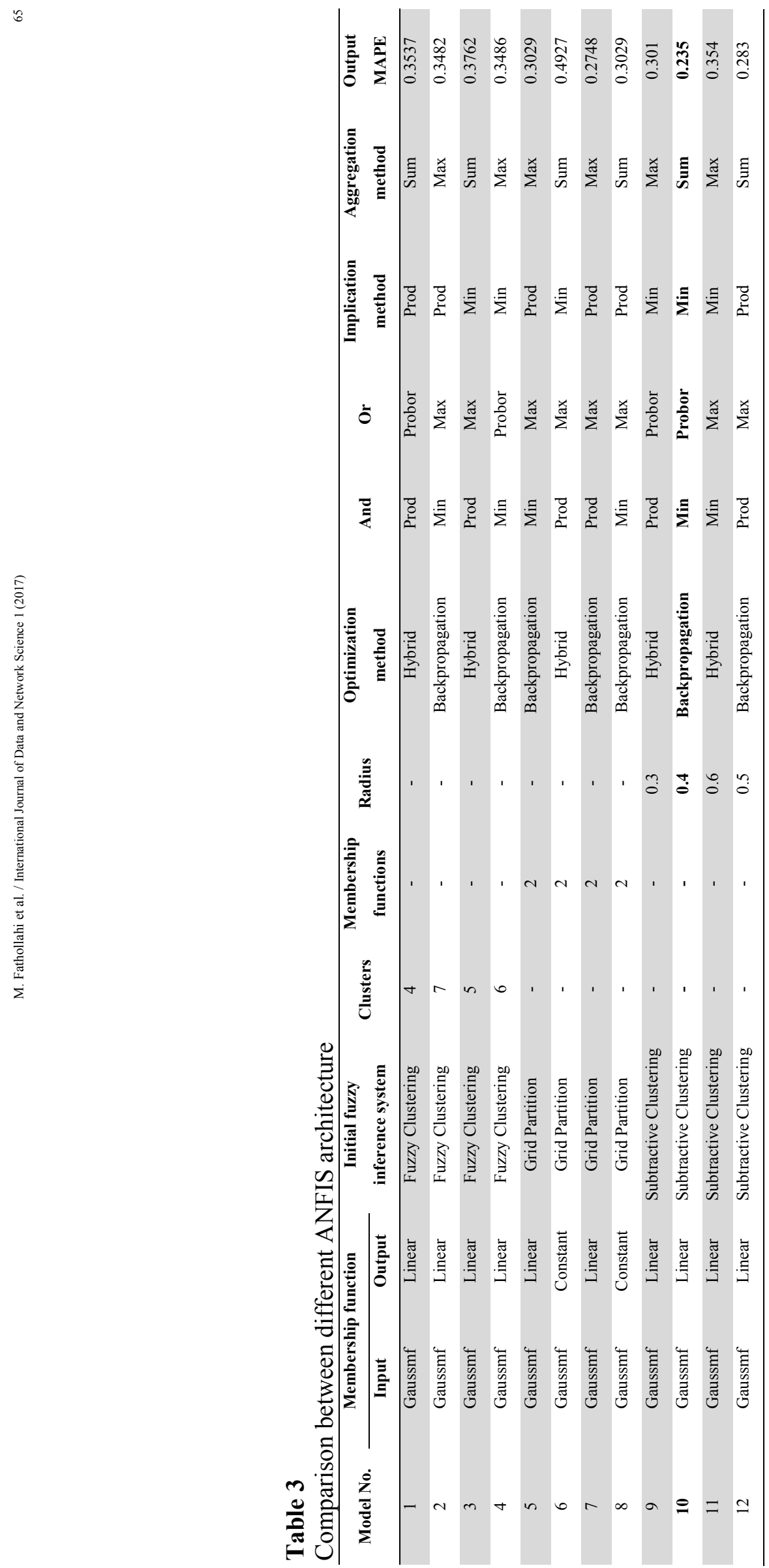




\section{Validation and Verification}

In this section, the analysis of variance (ANOVA) is exploited to select the best model among regression, ANN and ANFIS models. Let $\mu_{1}, \mu_{2}, \mu_{3}$ represent the estimated average of selected regression, ANN and ANFIS models respectively. Null hypothesis is defined in Eq. (4). Evaluation is done using SPSS 22 and is summarized in Table 4.

$$
\begin{aligned}
& H_{0}: \mu_{1}=\mu_{2}=\mu_{3} \\
& H_{1}: \mu_{i} \neq \mu_{j}, i \neq j, i, j=1,2
\end{aligned}
$$

\section{Table 4}

ANOVA output for solid waste generation

\begin{tabular}{cccccc}
\hline Source & SS & DF & MS & F & P \\
\hline Between Groups & 0.067 & 2 & 0.033 & 16.197 & 0.000 \\
Within Groups & 0.185 & 90 & 0.02 & - & - \\
\hline Total & 0.251 & 92 & - & - & - \\
\hline
\end{tabular}

SS: Sum of Squares; DF: Degrees of Freedom; MS: Mean Square; F: F test statistic; p: p-value (reports the significance level).

Based on this table, null hypothesis is rejected when $\alpha=0.05$.To find which average has meaningful difference, we apply Duncan's Multiple Range Test. In this test, series of pairwise comparison have been done and our two hypotheses are defined in Eq. (5).The results are shown in Table 5.

$$
\begin{aligned}
& H_{0}: \mu_{1}=\mu_{2}, \mu_{1}=\mu_{3}, \mu_{2}=\mu_{3} \\
& H_{1}: \text { otherwise }
\end{aligned}
$$

\section{Table 5}

Duncan test output for solid waste generation

\begin{tabular}{ccccccc}
\hline \multirow{2}{*}{$(\mathrm{I})$ VAR00004 } & (J) VAR00004 & $\begin{array}{c}\text { Mean Difference } \\
(\mathrm{I}-\mathrm{J})\end{array}$ & \multirow{2}{*}{ Std. Error } & \multirow{2}{*}{ Sig. } & \multicolumn{2}{c}{ 95\% Confidence Interval } \\
& & $-.05409^{*}$ & .01151 & .000 & -.0815 & Upper Bound \\
\hline \multirow{2}{*}{ ANFIS } & ANN & $-.05905^{*}$ & .01151 & .000 & -.0865 & -.0267 \\
& REG & $.05409^{*}$ & .01151 & .000 & .0267 & .0816 \\
\hline \multirow{2}{*}{ ANN } & ANFIS & -.00496 & .01151 & .903 & -.0324 & .0225 \\
\hline \multirow{2}{*}{ REG } & REG & $.05905^{*}$ & .01151 & .000 & .0316 & .0865 \\
& ANFIS & .00496 & .01151 & .903 & -.0225 & .0324 \\
\hline
\end{tabular}

*. The mean difference is significant at the 0.05 level.

Table 5 shows that the performance of ANFIS method is different from ANN and Regression methods, because $\mu_{1} \neq \mu_{2}$ and $\mu_{1} \neq \mu_{3}$. However performance of Regression and ANN methods are similar because $\mu_{2}=\mu_{3}$. Based on this observation and our previous experiments ANFIS had the least MAPE, we can conclude that ANFIS is more accurate method compared to regression approaches and ANN method (Nasiri et al., 2017b). Furthermore, two-sample t-test and f-test have been used to evaluate the equality of mean and variance of actual data and ANFIS prediction. These tests confirm that, from a statistical point of view, there is not significant difference between ANFIS and real data at $\alpha=0.05$. Results of this comparison are shown in the Table 6.

\section{Table 6}

Analysis of mean and variance between actual and ANFIS prediction

\begin{tabular}{ccccc|ccc}
\hline \multirow{2}{*}{ Treatment } & $\mathrm{n}$ & \multicolumn{4}{c|}{ F-test } & \multicolumn{3}{c}{$\mathrm{t}$-test } \\
\cline { 3 - 8 } & & $\mathrm{p}$-value & F-value & $H_{0}: \sigma_{1}^{2}=\sigma_{2}^{2}$ & $\mathrm{p}$-value & $\mathrm{t}$-value & $H_{0}: \mu_{1}=\mu_{2}$ \\
\hline ANFIS Result & 35 & 0.2252 & 1.5228 & Accepted & 0.8161 & -0.2344 & Accepted \\
\hline
\end{tabular}




\section{Conclusion}

Municipal solid waste generation is a major concern around the world especially in developing countries. In this paper, prediction of municipal solid waste of city of Tehran has been modeled as a time series based on the historical data (year 2006 to 2011). To achieve this goal, we have applied three widely used prediction methods: regression, ANN and ANFIS. In each of these methods, we have performed extensive experiments to understand the effect of relevant parameters. For example, in regression methods Exponential Smoothing has the least MAPE among other regression approaches. Next, the ANOVA test has been applied to select the best prediction method based on the MAPE metric. Since null hypothesis in the ANOVA test was rejected, Duncan's Multiple Range Test was used to determine which average had meaningful difference. Finally, we concluded that Regression and ANN method have similar performance and ANFIS was selected as the best method for prediction the solid waste generation in this case study. The selected ANFIS model have employed Gaussian membership function in the input layer, linear membership function for output layer, subtractive clustering in initial fuzzy inference system, and back propagation in optimization method. Furthermore, t-test and f-test have confirmed that from a statistical standpoint, there is no considerable difference between the real and predicted data. In future, we plan to extend this work to the whole city. Since different regions might have different waste generation pattern, more complex regression approach might be needed to better model the data. Another future improvement would be incorporating the society changes in the prediction model. For example, by transition to the fast food culture, more and more takeout plastic containers will be added to the municipal solid waste and previous regression models will not be able to precisely estimate MSW. Therefore the number of fast food companies/stores or their yearly production should be considered in the regression model.

\section{References}

Antanasijević, D., Pocajt, V., Popović, I., Redžić, N., \& Ristić, M. (2013). The forecasting of municipal waste generation using artificial neural networks and sustainability indicators. Sustainability science, 8(1), 37-46.

Azadeh, A., Asadzadeh, S. M., \& Ghanbari, A. (2010). An adaptive network-based fuzzy inference system for short-term natural gas demand estimation: uncertain and complex environments. Energy Policy, 38(3), 1529-1536.

Azadeh, A., Yazdanparast, R., Zadeh, S. A., \& Zadeh, A. E. (2017). Performance optimization of integrated resilience engineering and lean production principles. Expert Systems with Applications, 84, 155-170.

Bandyopadhyay, G., \& Chattopadhyay, S. (2007). Single hidden layer artificial neural network models versus multiple linear regression model in forecasting the time series of total ozone. International Journal of Environmental Science \& Technology, 4(1), 141-149.

Beede, D. N., \& Bloom, D. E. (1995). The economics of municipal solid waste. The World Bank Research Observer, 10(2), 113-150.

Chi, Y., \& ZHANG, D. P. (2005). HCl emission characteristics and BP neural networks prediction in MSW/coal co-fired fluidized beds. Journal of Environmental Sciences, 17(4), 699-704.

Denafas, G., Ruzgas, T., Martuzevičius, D., Shmarin, S., Hoffmann, M., Mykhaylenko, V., ... \& Turkadze, T. (2014). Seasonal variation of municipal solid waste generation and composition in four East European cities. Resources, conservation and recycling, $89,22-30$.

Dong, C., Jin, B., \& Li, D. (2003). Predicting the heating value of MSW with a feed forward neural network. Waste Management, 23(2), 103-106.

Dreiseitl, S., \& Ohno-Machado, L. (2002). Logistic regression and artificial neural network classification models: a methodology review. Journal of biomedical informatics, 35(5-6), 352-359.

Erdogan, R., Zaimoglu, Z., Sucu, M. Y., Budak, F., \& Kekec, S. (2008). Applicability of leachates originating from solidwaste landfills for irrigation in landfill restoration projects. Journal of environmental biology, 29(5), 779-784.

Gómez, G., Meneses, M., Ballinas, L., \& Castells, F. (2009). Seasonal characterization of municipal solid waste (MSW) in the city of Chihuahua, Mexico. Waste Management, 29(7), 2018-2024.

Hornik, K., Stinchcombe, M., \& White, H. (1989). Multilayer feedforward networks are universal approximators. Neural networks, 2(5), 359-366.

Karaca, F., \& Özkaya, B. (2006). NN-LEAP: A neural network-based model for controlling leachate flow-rate in a municipal solid waste landfill site. Environmental Modelling \& Software, 21(8), 1190-1197.

Kutner, M. H., Nachtsheim, C., \& Neter, J. (2004). Applied linear regression models. McGraw-Hill/Irwin. 
Liu, Z. F., Liu, X. P., Wang, S. W., \& Liu, G. F. (2002). Recycling strategy and a recyclability assessment model based on an artificial neural network. Journal of materials processing technology, 129(1-3), 500-506.

Manaf, L. A., Samah, M. A. A., \& Zukki, N. I. M. (2009). Municipal solid waste management in Malaysia: Practices and challenges. Waste management, 29(11), 2902-2906.

McCulloch, W. S., \& Pitts, W. (1943). A logical calculus of the ideas immanent in nervous activity. The bulletin of mathematical biophysics, 5(4), 115-133.

Minsky, M., \& Papert, S. (1969). Perceptrons Cambridge MA.

Mwenda, A., Kuznetsov, D., \& Mirau, S. (2014). Time series forecasting of solid waste generation in Arusha city-Tanzania. Mathematical Theory and Modelling, 4(8), 29-39.

Nasiri, M. M., Heidari, R., Yazdanparast, R., \& Akbarian, N. (2017a). Robust Possibilistic Programming Approach for the Design of Tehran Municipal Solid Waste Management System. Paper presented at the 13th International Conference on Industrial Engineering (IIEC 2017), Mazandaran, Iran.

Nasiri, M. M., Yazdanparast, R., \& Jolai, F. (2017b). A simulation optimisation approach for real-time scheduling in an open shop environment using a composite dispatching rule. International Journal of Computer Integrated Manufacturing, 30(12), 1239-1252.

Noori, R., Abdoli, M. A., Ghazizade, M. J., \& Samieifard, R. (2009a). Comparison of neural network and principal component-regression analysis to predict the solid waste generation in Tehran. Iranian Journal of Public Health, 38(1), $74-84$.

Noori, R., Abdoli, M. A., Farokhnia, A., \& Abbasi, M. (2009). RETRACTED: Results uncertainty of solid waste generation forecasting by hybrid of wavelet transform-ANFIS and wavelet transform-neural network.

Noori, R., Karbassi, A., \& Sabahi, M. S. (2010). Evaluation of PCA and Gamma test techniques on ANN operation for weekly solid waste prediction. Journal of Environmental Management, 91(3), 767-771.

Pamnani, A., \& Meka, S. (2015). Forecasting of municipal solid waste generation for small-scale towns and surrounding villages located in state of Gujrat, India. International Journal of Current Engineering and Technology, 5(1), $283-287$.

Qdais, H. A., Hani, K. B., \& Shatnawi, N. (2010). Modeling and optimization of biogas production from a waste digester using artificial neural network and genetic algorithm. Resources, Conservation and Recycling, 54(6), 359-363.

Rabbani, M., Heidari, R., Farrokhi-Asl, H., \& Rahimi, N. (2018). Using metaheuristic algorithms to solve a multi-objective industrial hazardous waste location-routing problem considering incompatible waste types. Journal of Cleaner Production, 170, 227-241.

Rhyner, C. R. (1992). Monthly variations in solid waste generation. Waste management \& research, 10(1), 67-71.

Rimaitytė, I., Ruzgas, T., Denafas, G., Račys, V., \& Martuzevicius, D. (2012). Application and evaluation of forecasting methods for municipal solid waste generation in an eastern-European city. Waste Management \& Research, 30(1), 89-98.

Rumelhart, D. E., McClelland, J. L, \& Group, PDP Research. (1986). Parallel Distributed Processing: Exploration in the Microstructure of Cognition. Foundations, Vol. 1 [M]: Canbridge, Massachusetts: MIT Press.

Shu, H. Y., Lu, H. C., Fan, H. J., Chang, M. C., \& Chen, J. C. (2006). Prediction for energy content of Taiwan municipal solid waste using multilayer perceptron neural networks. Journal of the Air \& Waste Management Association, 56(6), 852-858.

Skovgaard, M., Moll, S., \& Larsen, H. V. (2005). Outlook for waste and material flows. Baseline and alternative scenarios.

Strouboulis, J., Dillon, N., \& Grosveld, F. (1992). Developmental regulation of a complete 70-kb human beta-globin locus in transgenic mice. Genes \& Development, 6(10), 1857-1864.

Sy, N. L. (2006). Modelling the infiltration process with a multi-layer perceptron artificial neural network. Hydrological sciences journal, 51(1), 3-20.

Takahashi, F., Shimaoka, T., \& Kida, A. (2012). Atmospheric mercury emissions from waste combustions measured by continuous monitoring devices. Journal of the Air \& Waste Management Association, 62(6), 686-695.

Tiwari, M. K., Bajpai, S., \& Dewangan, U. K. (2012). Prediction of industrial solid waste with ANFIS model and its comparison with ANN model-A case study of Durg-Bhilai twin city India. International Journal of Engineering and Innovative Technology (IJEIT), 6(2), 192-201.

Toth-Nagy, C., Conley, J. J., Jarrett, R. P., \& Clark, N. N. (2006). Further validation of artificial neural network-based emissions simulation models for conventional and hybrid electric vehicles. Journal of the Air \& Waste Management Association, 56(7), 898-910.

Visvanathan, C, \& Trankler, J. (2003). Municipal solid waste management in Asia: a comparative analysis. Paper presented at the Workshop on Sustainable Landfill Management.

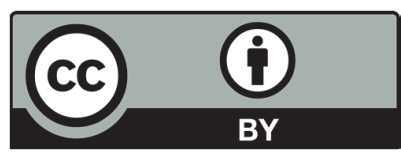

(C) 2017 by the authors; licensee Growing Science, Canada. This is an open access article distributed under the terms and conditions of the Creative Commons Attribution (CCBY) license (http://creativecommons.org/licenses/by/4.0/). 